Dissertation

\title{
Sharing Expertise within the MNC Is Increasingly Fluid and Challenging
}

\author{
Tuuli Hakkarainen ${ }^{1}$ a \\ 1 Bocconi University, Italy \\ Keywords: experts, global collaboration, multinational corporations, sharing expertise \\ https://doi.org/10.46697/001c.29913
}

\section{AIB Insights}

Vol. 21, Issue 4, 2021

\begin{abstract}
While multinational companies rely on their global expertise for gaining competitive advantage, sharing expertise has become increasingly fluid and challenging. This poses a major challenge to experts - individuals who are hired for their specialized skills and knowledge - as they work in multiple global teams simultaneously. The dissertation summary takes the perspective of experts and provides novel insight into the "new forms of collaborating," highlighting the importance of creating shared understanding, negotiating expertise, and gaining attention across teams and locations. The findings demonstrate that effective sharing expertise is a bottom-up process, in which individuals' efforts complement the team and organizational practices.
\end{abstract}

\section{BIG QUESTION}

How do experts navigate the increasingly fluid and challenging global collaboration in multinational corporations?

\section{INTRODUCTION}

Collaborating online and relying on "Zoomified" interactions became commonplace to knowledge workers across industries during the global pandemic. Many had their first hands-on experience of working extensively online without the same supporting factors we used to rely on in an inperson environment. For example, creating shared understanding, negotiating expertise, or gaining attention to our ideas and viewpoints have become central challenges when we cannot observe or interpret each other in the same way as when having the possibility to physically meet or have a chat over coffee. While the global pandemic disrupted the routines of knowledge workers almost overnight globally (Caligiuri, De Cieri, Minbaeva, Verbeke, \& Zimmermann, 2020), navigating complex global collaboration had already been the reality for experts in multinational corporations for many years. My dissertation, which is summarized herein, focuses on the perspective of these experts working in multinational corporations (MNCs) to gain new insights on effective expertise sharing and learn about their various challenges and approaches for making global collaboration work. These "expert insights" can now benefit a range of organizations dealing with increasingly fluid and challenging expertise sharing.
The success of the MNC lies in its capability to effectively utilize its globally distributed expertise (Kogut \& Zander, 1993). Expertise refers to the specialized knowledge individuals possess and enact in an active process of expertise sharing, which is practical, situated, and relational (Bourgoin, Bencherki, \& Faraj, 2020). This conceptualization differs from that of knowledge transfers, in which knowledge primarily refers to the possession of knowledge that is transferred between units. By using the term expertise sharing (and not, for example, knowledge sharing), I include the technical knowledge that is shared but emphasize the complex social process, which includes active expertise negotiation and thus goes beyond the possession of knowledge. Recognizing both the strategic value and the uniqueness of expertise, leading companies are shifting toward more global, flexible, and expertise-centric collaboration practices (Deloitte, 2019). In practice, this implies that collaboration increasingly takes place between individuals across geographical, cultural, functional, and also team boundaries. Such boundaries have become central for the global and digital work of today. Accordingly, investigating expertise sharing has become a topical challenge for both academia and corporate practice.

While globally distributed expertise is a source of significant competitive advantage for the MNC to foster synergies, integrate knowledge, and nurture innovation (Kogut \& Zander, 1993), sharing expertise can be - and most often is - a major source of friction. For example, domain-specific knowledge is not always readily available across boundaries, such as between teams and locations, which can cause misunderstanding, make understanding each other's exper-

\footnotetext{
a Ph.D. awarded by Aalto University, Finland (December 2020) Dissertation title: Sharing expertise within the MNC
} 
tise difficult, or impede gaining attention from others. Recognizing the inherent tensions present in the complex MNC, previous research has made important advances in understanding inter-unit knowledge transfers (Ghoshal, Korine, \& Szulanski, 1994), global teams (Haas \& Cummings, 2015), and boundary spanners (Mäkelä, Barner-Rasmussen, Ehrnrooth, \& Koveshnikov, 2019).

What emerges from the vast literature on knowledge transfers is that research has mainly focused on relatively stable collaboration settings, such as fixed units, roles, or stable team structures. However, life in modern MNCs is increasingly fluid and sharing expertise does not always coincide neatly with specific units or within clearly bounded teams (Mortensen \& Haas, 2018). Instead, experts of different domains, such as engineers, designers, or business developers, work in different locations, positions, and teams, and thus interact with each other in flexible ways to solve complex problems together. This situation directs attention to the role of key individuals working in different constellations, leading to an important question: How do experts navigate the increasingly fluid and challenging global collaboration in multinational corporations?

In this dissertation summary, I provide novel insights into sharing expertise within the MNC, using the everyday collaboration of experts as the starting point. I draw from an extensive qualitative dataset of 75 in-depth interviews with different functional experts (e.g., engineers, specialists) in four MNCs as well as observations of their meetings in one of them. Next, I will focus on three main findings creating shared understanding, negotiating expertise, and gaining attention (See Figure 1) - and discuss the key takeaways for managers and experts.

\section{EXPERT INSIGHT I: CREATING SHARED UNDERSTANDING IS INDIVIDUAL-DRIVEN IN GLOBAL COLLABORATION}

The first expert insight relates to creating shared understanding, which is a fundamental aspect of effective expertise sharing. Without "being on the same page," it is easy to misinterpret what others are saying or become misunderstood, and conflicts can follow. This poses a challenge for experts in MNCs more than before. To begin with, there is the geographical distance, which means that individuals cannot observe each other, rely on getting to know each other's ways of working, unlike if they had the possibility to observe each other in person. Also, coming from different locations and cultures can mean having different underlying assumptions which can cause misunderstandings. In addition to these boundaries, most recently, experts are more likely to work in multiple global teams simultaneously. This compounds the issue as experts must divide their attention amongst multiple teams, increasing the difficulty of achieving common ground with others in many ways. For example, experts in MNCs cannot always build on team familiarity, shared practices, or supporting context (e.g., same location or team) - aspects that traditionally are known to support shared understanding. Instead, they rely on their personal strategies to create shared understanding. This differs from stable global teams, for example, which can rely

1) CREATING SHARED UNDERSTANDING

(e.g. CLARIFYING TECHNICAL, SOCIAL OR EXPERTISE-BASED DIMENSIONS)

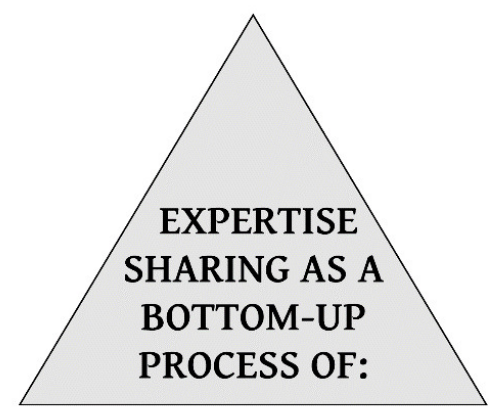

2) NEGOTIATING EXPERTISE THROUGH THE USE OF LANGUAGE
3) GAINING ATTENTION TO IDEAS AND VIEWPOINTS THROUGH COMPETENCE

BY INDIVIDUALS IN THE MULTINATIONAL CORPORATION CONTEXT

\section{Figure 1. Synthesis of the Three Expert Insights}

on explicit socialization processes supported by leaders in global teams. Now "getting this done" has increasingly become the responsibility of experts themselves.

What is often emphasized is that in global teamwork, misunderstandings are associated with cultural differences. However, as project teams combine expertise from different fields, the main findings indicate that "the language of expertise" also matters - if not even more than traditional demographic factors. Experts can use different terms although they would talk about the exact same thing and just think they disagree. What makes these misunderstandings particularly difficult is that they can be hard to detect as takenfor-granted assumptions tend to be deeply rooted. Interestingly, the specialization that is needed to become an expert, in collaboration easily becomes a barrier. To avoid hurdles in collaboration, experts showed constant efforts to stop and think whether a misunderstanding relates directly to the common task or could be explained by differences in personal approaches or work environments, or if the source of tension is expertise-related, such as differences in vocabulary or priorities. Taking time to figure this out is crucial to shared understanding, but has become largely the responsibility of individuals, and not their existing team practices or actions of team leaders, which makes the challenge less visible but highly central to effective global collaboration.

\section{EXPERT INSIGHT II: NEGOTIATING EXPERTISE EMPHASIZES THE USE OF LANGUAGE}

The second expert insight relates to expertise and how it is negotiated in collaboration. But what makes an expert? What seems first as an obvious question - "textbook" answers ranging from having expert credentials and experience in a specialized field as well as being recognized by 
others as an expert - quickly becomes complicated when approached from a practical perspective. By merely having expert credentials (e.g., Ph.D.), are you an expert in any context? For example, I can be an expert of expertise sharing in MNCs - but maybe only in the eyes of my peers or outside academia, as people could approach me having recently defended the Ph.D. thesis on the topic. However, within academia, I have just started to understand expertise sharing and many before me have built full careers on the study of professions, specialization, knowledge sharing in MNCs, and so on - making them the "go-to" people on the topic.

So, expertise depends on the context and is always relative. When taken to the company environment, when I posed these questions to the study participants, they often responded that "of course" one needs to have expert credentials and be an expert in others' eyes, but very quickly they added that "even a wealth of knowledge does not mean much unless it is made useful in the firm." These responses emphasized the process of "doing" expertise. For example, one can have fifteen years of experience, but unless the expert can explain to others what it means and others can understand how that expertise is useful and how it can be combined with what others know, it does not add value to joint problem solving. Thus, "what makes an expert" refers to the complex social process of "doing" expertise - in addition to "having" expertise and "being" an expert. Doing expertise is often needed to advance one's own or a team's goals or to strengthen social status within a group, which can be met with resistance by others.

In sum, rather than viewing expertise as static or universal, or being encapsulated in roles or job descriptions, "doing” expertise is key. This is particularly important in today's knowledge work in which individuals work in multiple projects simultaneously, creating a need to enter and exit assignments as needed, thus requiring them to constantly find ways to "do" expertise and negotiate their expertise "anew." Without familiarity with other project members or having years of working together and knowing each other's expertise, individuals need to actively make efforts to share their expertise, making "doing” expertise crucial. Thus, "doing" expertise can be seen, for example in meetings as critical moments of expertise sharing, which can be subtle talk or brief negotiation taking place in collaboration. For example, moments of claiming expertise ("I know": "I have experience in"), signaling control ("So, let's"; "You should”) and positioning their expertise within the broader firm ("As our team is aware"; "They might think") show that expertise is actively enacted through language - thus going beyond the possession of knowledge.

\section{EXPERT INSIGHT III: COMPETENCE IS KEY TO GAINING ATTENTION IN GLOBAL COLLABORATION}

The third expert insight relates to gaining attention. Although winning attention has been recognized among the most sought-after resources in MNCs in general, it has become even more scarce in the fragmented collaboration in which individuals are competing for attention from each other across multiple simultaneous global teams. Attention is needed to move agendas and projects forward; yet, lacking attention to one's ideas and viewpoints can lead to frustration. In my study, experts described situations in which they struggled with "getting an answer" and "hearing from the other side" when they would need to provide their expert insight or raise concerns in different areas of the project they are responsible for. Gaining attention is challenging from others whom they have never met. This describes a typical situation in global collaboration; yet experts do not possess managerial influence or authority to demand gaining attention when and how they need it, unlike managers who are more able to draw from their positional and relational basis of attention. What emerges is that experts need to find alternative ways to gain attention in the increasingly complex global collaboration to "get things done."

What experts can do is to draw from their most available resource: their competence. I found that personal competence is required to gain attention through internal legitimacy, whereas team competence provides the necessary external legitimacy, for example, to gain the attention of external project collaborators. Competence-based attention in this sense differs from the formal, role-based authority through which individuals in managerial positions gain attention using various influence tactics (Bouquet \& Birkinshaw, 2008).

Being recognized as an expert can direct the team's focus on issues that require attention. However, as we have now learned, not all required expertise sharing is located within the team but requires also reaching out to others, such as other colleagues outside the familiar team, function, or location. For example, when an expert (e.g., an engineer, designer, product owner) needs access to the customer needs to improve the focal project's deliverables, the expert needs to discuss his or her viewpoints with a business representative. Without familiarity, this might not be an easy boundary to cross. In these cases, experts in our study described in various ways how they can draw from their collective competence, such as the visibility and expertise of their team(s). For example, if the team is specialized in manufacturing, the expert can draw from this collective source of competence to gain attention and thus establish external legitimacy for the needed inputs. As with other challenges and personal approaches discussed above regarding creating shared understanding and negotiating expertise, gaining attention depends on the efforts and proactivity of the individual experts to navigate the fluid collaboration in MNCs today.

\section{SO, WHAT CAN MANAGERS DO? TUNE IN TO THE EVERYDAY COLLABORATION OF EXPERTS}

Making collaboration work is not only "nice to have," but strategically important for multinational companies (MNCs) to develop sustained competitive advantage. Amazon, Google, and other MNCs across industries highly rely on the specialized knowledge of their experts and their ability to effectively collaborate across locations and teams to deliver products and services on time. As all three expert insights point to, understanding an individual's perspective 
of strategically important work of expertise sharing is crucial when aiming to learn about today's fragmented work. While listening to customers to understand their wants and needs is a common strategy for firms to gain a competitive edge and develop their offerings, managers could learn also by listening to their experts. Importantly, fetching the expert's perspective could prove useful not only when technical inputs are considered, but also regarding everyday collaboration.

For example, organizations could establish practices that go beyond the focus on technology enabling global teamwork to emphasize the interpersonal skills of their employees in projects, such as by allowing new project teams enough time to get to know each other. Also, supporting the process of creating shared understanding by mentoring and discussing the wide range of possible sources of misunderstandings and taken-for-granted assumptions could help solve or prevent some of the interpersonal aspects of collaboration. However, what makes these individual efforts less obvious, and thus a managerial challenge, is that they are to a great extent organic, bottom-up processes, which cannot be fully captured by top-down management. Instead, besides supporting technical processes, attention could also be given to the "human side" of multi-teaming, such as providing on-the-job opportunities to build "soft" skills such as empathy (e.g., seeing the problem through other's eyes) and being proactive about different ways of collaborative problem solving (e.g., clarifying central and peripheral roles in multi-teaming up front, making takenfor-granted assumptions explicit).

\section{WHAT CAN I DO AS AN EXPERT TO IMPROVE EXPERTISE SHARING IN MY TEAM(S) OR ORGANIZATION?}

Given that effective expertise sharing is the responsibility of each of us, taking the time to self-reflect can be a helpful first step. I have listed some of the guiding questions, which are based on my in-depth interviews and observations with experts in four MNCs.

- How can I simplify my language (e.g., utilize more concrete examples, avoid jargon) to help others better grasp the value of my expertise I bring to the team?

- How can I make my taken-for-granted assumptions (whether technical, related to the social context, or expertise-based) explicit to others to avoid misunderstandings?

- How can I make more effort to understand others' perspectives? For example, what might others priori- tize, be sensitive to or find critical that I might need to be more attentive to?

- How can I gain more control in meetings by paying attention to how I talk about my expertise when and where these opportunities to use my voice arise?

- How can I best contribute with my expertise by gaining more attention to my ideas and viewpoints, both as an individual and part of my team(s)?

\section{CONCLUSION}

This summary has focused on three expert insights related to the importance of understanding the individual expert's perspective for effective expertise sharing in today's MNCs in which collaboration is increasingly fluid and challenging. More specifically, tuning in to how experts navigate their collaboration is crucial when aiming to design supporting practices related to the common challenges of creating shared understanding, negotiating expertise, and gaining attention. These findings indicate that besides understanding their customers' wants and needs, managers can learn a great deal by listening to their expert workers not only when technical insights are sought for but as the drivers and creators of the best practices for "new forms of collaborating."

\section{ACKNOWLEDGMENTS}

The author thanks her Ph.D. supervisor Kristiina Mäkelä and other co-authors of the dissertation essays, Niina Nurmi and Jo Angouri, as well as Business Finland for the funding.

\section{ABOUT THE AUTHOR}

Tuuli Hakkarainen obtained her Ph.D. from Aalto University and currently works at Bocconi University. Tuuli's dissertation examines global expertise sharing from the perspective of individuals. The dissertation has received the AIB Award for the Best Doctoral Dissertation Proposal at the Academy of International Business (AIB) 2019, The Michael Z. Brooke Prize in AIB UK \& Ireland Chapter 2018, and has been nominated as the runner up for Copenhagen Business School Prize at European International Business Academy (EIBA) 2017.

Submitted: July 28, 2021 EST, Accepted: September 28, 2021 EST 


\section{REFERENCES}

Bouquet, C., \& Birkinshaw, J. 2008. Weight versus voice: How foreign subsidiaries gain attention from corporate headquarters. Academy of Management Journal, 51(3): 577-601.

Bourgoin, A., Bencherki, N., \& Faraj, S. 2020. "And who are you?": A performative perspective on authority in organizations. Academy of Management Journal, 63(4): 1134-1165.

Caligiuri, P., De Cieri, H., Minbaeva, D., Verbeke, A., \& Zimmermann, A. 2020. International HRM insights for navigating the COVID-19 pandemic: Implications for future research and practice. Journal of International Business Studies, 51(1): 697-713.

Deloitte. 2019. Leading the social enterprise: Reinvent with a human focus. 2019 Deloitte Global Human Capital Trends.

Ghoshal, S., Korine, H., \& Szulanski, G. 1994. Interunit Communication in Multinational Corporations. Management Science, 40(1): 96-110.
Haas, M. R., \& Cummings, J. N. 2015. Barriers to knowledge seeking within MNC teams: Which differences matter most. Journal of International Business Studies, 46(1): 36-62.

Kogut, B., \& Zander, U. 1993. Knowledge of the firm and the evolutionary theory of the multinational corporation. Journal of International Business Studies, 24(4): 625-645.

Mäkelä, K., Barner-Rasmussen, W., Ehrnrooth, M., \& Koveshnikov, A. 2019. Potential and recognized boundary spanners in multinational corporations. Journal of World Business, 54(4): 335-349.

Mortensen, M., \& Haas, M. 2018. Rethinking teams: From bounded membership to dynamic participation. Organization Science, 29(2): 341-355. 